\title{
Secondary Crisis Communication. A question of Actual or perceived credibility?
}

\author{
Bengt Johansson \\ University of Gothenburg \\ Seminariegatan 1b, 40530 \\ Gothenburg, Sweden
}

\begin{abstract}
An important aspect of crisis communication is secondary crisis communication, which focuses on how people communicate during a crisis. This study seeks to explore the mechanism of credibility in secondary crisis communication. Respondents in a large-scale experiment $(\mathrm{N}=2382)$ were exposed to a fictional news story about a terrorist attack and asked to what degree they would share the news story on social media. The design made it possible to test if the sharing of news stories was determined by its actual credibility (through the use of semiotic disclaimers in the news story), or by perceived credibility (the perceived credibility of the news story). Other factors, such as the severity of the threat in the story, trust in news media, to what extent emotions were evoked by the news story, gender, and age, were used as controls. Results indicated that the perceived credibility was more important than the actual message credibility.
\end{abstract}

Keywords - Credibility, News, Disclaimers, Experiment design, Secondary crisis communication

SUGGESTED CITATION: Johansson, B. (2019). Secondary crisis communication. A question of actual or perceived credibility? Proceedings of the International Crisis and Risk Communication Conference, Volume 2 (pp. 44-46). Orlando Fl.: Nicholson School of Communication and Media. https://doi.org/10.30658/icrec.2019.13

\section{INTRODUCTION}

Secondary crisis communicating is an important aspect of crisis communication. There are a number of reasons why we share information during crises. Previous research has indicated that perceived threat severity has an impact, but even individual factors such as gender seem to be important. One crucial factor in communication is credibility. From media research, we have learned that credibility is central for media usage and effects. However, is credibility also determining secondary crisis communication? If so, does the actual credibility matter or is it just a question of perception? The study seeks to answer this question by using a vignette large-scale experiment. The continuing structure of the paper is as follows. The first section contains a review of secondary crisis communication research. Thereafter follows methodology, were design of the experiment in the study is described. The results of the study is presented in the following section and the last section discuss the lessons learned, limitations, and proposals for further research,

\section{LITERAURE REVIEW}

Secondary crisis communication has received attention in research during the last decade, especially related to social media. Research has pointed out a number of reasons why people share information during a crisis, such as alerting family or friends (or a wider audience), calming family and friends, make sure family and friends are safe, confirming crisis information, organizing emergency response and seeking emotional support and healing [1] [2].

Previous research has also pointed out different determinants for secondary crisis communication, such as perceived threat severity [3] and to what extent respondents are affected by the crisis [4]. Demographics, such as gender seems also to be an important factor for sharing information during crises [5].

A factor not yet tested in explaining secondary crisis communication, is message credibility. We know from extensive research on media usage and media effects how important credibility is in communication [6], and therefore this study seeks to investigate if message credibility - both actual and perceived - will affect to what extent people share information in a crisis. 


\section{METHODOLOGY}

A large-scale vignette $(\mathrm{N}=2382)$ experiment was used to examine to what extent message credibility affected the willingness to share information. Participants were exposed to a fictional, yet realistic, news story about a possible terrorist attack. In the experiment, participants read a breaking story of a possible knife attack close to the Swedish parliament in Stockholm. The level of uncertainty around the event was varied through the use of disclaimers, which made the stories differ in terms of credibility. To capture secondary crisis communication (dependent variable), respondents were asked how likely it was that they would share the news story about the knife-attack on social media. Exposure to treatment with different use of disclaimers was used to measure actual credibility, and two questions where respondents answered how actual and trustworthy they believed the story was, were merged into a measure of perceived credibility. A number of other independent variables were included as controls (threat severity, trust in news media, emotions evoked by the treatment, gender, and age).

\section{RESULTS}

Results showed a rather low willingness to share the stories on social media. Only 23 percent of those using social media ( 8 percent claimed they did not use social media and were excluded from the analysis). The further analysis builds on a number of multiple regressions (table 1) which showed a strong support for perceived credibility as a predictor of secondary crisis communication (beta $=.21, \mathrm{p}<.000$ ). Actual credibility seems to matter less, since no significant difference was detected related to if participants were exposed to message with different message credibility (i.e. use of disclaimers with different strength).

Table 1. Predictors explaining secondary crisis communication (standardized regression coefficients).

\begin{tabular}{|c|c|c|c|c|c|c|}
\hline & Model 1 & & Model 2 & & Model 3 & \\
\hline Actual credibility & .01 & & & & .01 & \\
\hline Perceived credibility & .21 & $* * *$ & & & .13 & $* * *$ \\
\hline \multicolumn{7}{|l|}{ Controls } \\
\hline Threat severity & & & .02 & & & \\
\hline Trust in news & & & -.07 & $* * *$ & -.09 & $* * *$ \\
\hline \multicolumn{7}{|l|}{ Emotions evoked } \\
\hline Afraid & & & .17 & $* * *$ & .16 & $* * *$ \\
\hline Angry & & & .16 & $* * *$ & .12 & $* * *$ \\
\hline Sad & & & .04 & & .02 & \\
\hline Gender & & & .04 & & .04 & \\
\hline Age & & & -.05 & $*$ & -.05 & $*$ \\
\hline Adjusted $\mathrm{R}^{2}$ & $4 \%$ & & $10 \%$ & & $11 \%$ & \\
\hline $\mathrm{N}$ & 2187 & & 2090 & & 2089 & \\
\hline
\end{tabular}

Comment: $* p<.05 . * * p<.01 . * * * p<.001$.

A number of controls showed direct effects on sharing information on social media after being exposed to the treatment. Respondents claiming to be afraid (beta $=.17, \mathrm{p}<.000$ ) or angry (beta $=.16, \mathrm{p}<.000$ ) afterwards where more likely to share. The same holds for younger participants (beta $=-.05, \mathrm{p}<.05$ ). A bit surprising is perhaps that trust in news media was related negatively to sharing information (beta $=-.07, \mathrm{p}<.000$ ). Those having less trust in news media where more prone to sharing on social media.

When exploring the complete model (model 3), there are no significant changes from the previous (model 1 and 2 ). Perceived credibility was still important for sharing, while actual credibility was not. Controls showing significant effect in model 2 were still significant in the complete model (model 3).

\section{DISCUSSION}

Previous research has tried to detect functions and determinants for secondary crisis communication. This study gives another piece to the puzzle of understanding why people share information on social media during crises. If we first consider the direct effects of the controls, people seem to share information if the crisis messages evokes feelings (fear or anger). Younger people are also more eager to use social media and will probably share everything more than older respondents - independent of whether the story is about a crisis or not. One possible explanation for the relationship between distrust in news media and secondary crisis communication could be that being active on social media also often is related to distrust in legacy media.

When it comes to credibility, we did not find any effect of the actual credibility related to sharing information on social media, instead perceived credibility seems to be more important.

What are the implication of this study? The first lesson to learn is that if people believe the message is credible, they will more likely share information. The second lesson might be that the disclaimers used in this experiment are too weak to make 
people see the messages as less credible and thus treat them with caution. The third lesson is that if you want a crisis message to he shared, it should evoke emotions. A fourth is you should trust on young people if you want crisis messages to be shared on social media.

There are of course a number of limitations in this study. First, we are just testing secondary crisis communication with one case, and this case is not a particular threatening story if you or your friends or family are not close to the place where the story was said to occur. As we already touched upon, the disclaimers in the treatment where perhaps not strong enough to create strong reactions. We might have detected effects of actual credibility with less credible messages.

Given that perceived credibility seems to be a strong predictor of secondary crisis communication, future research should put emphasis on investigating this mechanism further. The credibility of different platforms and senders for secondary crisis communication needs to be further investigated. Another possible way to go is to expand secondary crisis communication and credibility to include other forms of secondary crisis communication, such as personal communication and other forms of mediated communication.

\section{AUTHOR BIOGRAPHY}

Bengt Johansson, $\mathrm{PhD}$ at University of Gothenburg, Sweden. Current position: Professor at the Department of Journalism, Media and Communication, University of Gothenburg. SWEDEN. bengt.johansson@jmg.gu.se

\section{REFERENCES}

[1] Liu, B. F., Fraustino, J. D., \& Jin, Y. (2016). Social media use during disasters: How information form and source influence intended behavioral responses. Communication Research, 43, 626 - 646. https://doi.org/10.1177/0093650214565917

[2] Anthony, K. E., Sellnow, T. L., \& Millner, A. G. (2013). Message Convergence as a message-centered approach to analyzing and improving risk communication, Journal of Applied Communication Research, 41, 346 - 364. https://doi.org/10.1080/00909882.2013.844346

[3] Sheldon, P. (2018) Emergency alert communications on college campuses: understanding students' perceptions of the severity of a crisis and their intentions to share the alert with parents and friends. Western Journal of Communication, 82(1), 100-116. https://doi.org/10.1080/10570314.2017.1308005

[4] Austin, L., Liu, B.F. \& Jin, Y (2012) How audiences seek out crisis information: exploring the social-mediated crisis communication model. Journal of Applied Communication Research, 40, 188 - 207. https://doi.org/10.1080/00909882.2012.654498

[5] Sheldon, P. \& Antony, M. G. (2018) Sharing emergency alerts on a college campus: How gender and technology matter. Southern Communication Journal, 83. 167-178. https://doi.org/10.1080/1041794X.2018.1437467

[6] Hovland, C. I. \& Weiss, W. (1951). The influence of source credibility on communication effectiveness. Public Opinion Quarterly, 15, 635-650. https://doi.org/10.1086/266350 